\title{
Nanoparticle Size Effect on Water Vapour Adsorption by Hydroxyapatite
}

\author{
Urszula Szałaj ${ }^{1,2, *}$, Anna Świderska-Środa ${ }^{1}$, Agnieszka Chodara ${ }^{1,2}$, Stanisław Gierlotka ${ }^{1}$ \\ and Witold Łojkowski ${ }^{1}$ \\ 1 Institute of High Pressure Physics, Polish Academy of Sciences, Sokołowska 29/37, 01-142 Warsaw, Poland \\ 2 Faculty of Materials Engineering, Warsaw University of Technology, Wołoska 41, 02-507 Warsaw, Poland \\ * Correspondence: u.szalaj@labnano.pl; Tel.: +48-22-876-04-31
}

Received: 12 June 2019; Accepted: 10 July 2019; Published: 12 July 2019

\begin{abstract}
Handling and properties of nanoparticles strongly depend on processes that take place on their surface. Specific surface area and adsorption capacity strongly increase as the nanoparticle size decreases. A crucial factor is adsorption of water from ambient atmosphere. Considering the ever-growing number of hydroxyapatite nanoparticles applications, we decided to investigate how the size of nanoparticles and the changes in relative air humidity affect adsorption of water on their surface. Hydroxyapatite nanoparticles of two sizes: 10 and $40 \mathrm{~nm}$, were tested. It was found that the nanoparticle size has a strong effect on the kinetics and efficiency of water adsorption. For the same value of water activity, the quantity of water adsorbed on the surface of $10 \mathrm{~nm}$ nano-hydroxyapatite was five times greater than that adsorbed on the $40 \mathrm{~nm}$. Based on the adsorption isotherm fitting method, it was found that a multilayer physical adsorption mechanism was active. The number of adsorbed water layers at constant humidity strongly depends on particles size and reaches even 23 layers for the $10 \mathrm{~nm}$ particles. The amount of water adsorbed on these particles was surprisingly high, comparable to the amount of water absorbed by the commonly used moisture-sorbent silica gel.
\end{abstract}

Keywords: adsorption; hydroxyapatite; nanoparticles; size effect; size dependent; water layers; humidity; ambient conditions

\section{Introduction}

Exploitation of the specific properties of nanomaterials, which are not observed in their microcrystalline counterparts, is a fundamental basis of nanotechnology [1]. Due to these properties, nanoparticles are increasingly applied as additives, modifiers of composite materials, reaction catalysts $[2,3]$, nano-solders [4,5], sensors [6-8], coatings $[9,10]$ and materials for medical applications [11-16]. Over the past few decades, millions of tons of nanoparticles have been produced [17]. Nanoparticles dispersed in a base material may act as the nucleus of new phases, facilitate its hydration, and reinforce and compact the microstructure, thus reducing the material's porosity [18]. The large specific surface area of nanomaterials leads to sorption processes on their surfaces. As a result, these materials can bind water contained in the air even during production processes. Depending on the application of a given nanomaterial, the water adsorbed on the nanoparticle surface may be either beneficial or unfavourable [19].

Nanotechnology and nanomaterials are very promising for modern medicine. A frequently applied bio-nanomaterial is hydroxyapatite (HAP), which is a mineral that naturally occurs in the form of calcium apatite. Composites composed of HAP nanocrystals and biocompatible polymers are widely used in orthopaedics [20-22] and dentistry [23,24]. Dispersing the hydroxyapatite in a polymer reinforces its mechanical properties and improves osteoinductiveness and biocompatibility [25-27]. Water adsorption by hydroxyapatite attracted considerable interest since the 1960s/1970s due to the 
application of this material in dentistry, and sorption processes occurring on microcrystalline, synthetic, and natural hydroxyapatite were described [28-31]. The ionic nature of HAP was indicated as the cause of strong bonds forming between polar adsorbates and the hydroxyapatite surface [28]. To verify that theory, Dry and Beebe [28] researched the adsorption heat of water and ethanol on microcrystalline hydroxyapatite and determined the adsorption isotherms. It was found that both types of adsorbates were bonded on the HAP surface by hydrogen bonds. In addition, the water molecules were bonded by means of a single hydrogen bond. After covering the surface of microcrystalline hydroxyapatite with one layer of water, it was possible to add another layer of molecules. Dry and Beebe emphasised that, in the case of microcrystalline hydroxyapatite, it was very difficult to distinguish physical adsorption of water molecules from chemical adsorption.

Rootare and Craig [29] examined sorption processes for microcrystalline HAP with different specific surface areas of 3,22 , and $70 \mathrm{~m}^{2} / \mathrm{g}$. Water adsorption isotherms and adsorption heat at a temperature of $300{ }^{\circ} \mathrm{C}$ were calculated, and the number of water molecule layers was established to be 8,9 , and 15, respectively. According to Rootare and Craig, the first layer of water molecules was bonded by HAP in a chemisorption process, whereas successive layers were added in a physical adsorption process. Holmes and Beebe [30] found that the quantity of water bonded to the microcrystalline HAP surface depended on the sample history.

Wade et al. [31] attempted to determine the impact of relative air humidity on hydroxyapatite compactness. The moisture content of granulated hydroxyapatite was determined using thermogravimetric analysis (TGA) within the temperature range from $25^{\circ} \mathrm{C}$ to $450{ }^{\circ} \mathrm{C}$. The total mass loss of the sample stored at a temperature of $20{ }^{\circ} \mathrm{C}$ and with $\mathrm{RH}=30 \%$ amounted to $5.26 \% \pm 0.04 \%$. According to the authors, about $0.7 \%$ of the weight was loosely bounded water, which was lost at temperatures from $20^{\circ} \mathrm{C}$ to $60^{\circ} \mathrm{C}$. About $0.5 \%$ of the mass was lost by degassing water from the surface of the granulated HAP at temperatures from $60{ }^{\circ} \mathrm{C}$ to $100{ }^{\circ} \mathrm{C}$. At temperatures from $100{ }^{\circ} \mathrm{C}$ to $450{ }^{\circ} \mathrm{C}$, approximately $4 \%$ of the sample weight was lost as a result of the desorption of water adsorbed by the chemisorption process.

Hydroxyapatite with a nanometric particle size is attracting considerable interest. Hydroxyapatite nanocrystals contained in human bones are 5-20 nm wide and $60 \mathrm{~nm}$ long [32]. Therefore, synthetic nano-hydroxyapatite is particularly valuable for use in regenerative medicine since its particle size is similar to that of natural HAP. Nano-HAP is also widely used in toothpaste, cosmetics, and products that fill wrinkles (in conjunction with hyaluronic acid) [33,34].

In the fields of pharmacy and regenerative medicine, control of the hydrophilic properties of materials is very desirable [32,35-37]. For example, the addition of a hydrophilic filler to hydrophobic Polylactic acid PLA allows nano-fibres to be produced from this hydrophilic composite. The addition of a hydrophilic filler, e.g., hydroxyapatite, also improves the mechanical properties and biocompatibility of the implant [38-41]. On the other hand, too much additive can cause significantly decreased tensile strength of PLA/HA composites and faster composite degradation [42,43]. Another important example is the change in the tensile strength of ibuprofen and paracetamol tablets with moisture content. A low moisture content (in the range $1 \%$ to $4 \% \mathrm{w} / \mathrm{w}$ ) in tablets increases the tensile strength $[40,44-46]$. Exceeding the limit value of the water content in the tablet results in a significant reduction in tensile strength and disintegration [47]. An understanding of sorption properties is needed to enable control over the quantity of water that is adsorbed by a given nanomaterial.

We studied the sorption properties of GoHAP ${ }^{\mathrm{TM}}$ with particle sizes of 10 and $40 \mathrm{~nm}$ [48] in order to compare these adsorption properties of nanomaterials and their microcrystalline counterparts. GoHAP ${ }^{\text {TM }}$ nanoparticles were produced by the hydrothermal method of microwave synthesis in the MSS-2 reactor, which is a unique method that allows nanoparticles with a controlled particle size to be obtained. This technique can be applied not only to hydroxyapatites, but also to metal oxides such as $\mathrm{ZnO}$ and $\mathrm{ZrO}_{2}$ as well as doped metal oxides. Microwave synthesis enabling control of particle size has been precisely described [32,49-55]. Due to the high surface area of such small nanoparticles, on the order of $200 \mathrm{~m}^{2} / \mathrm{g}$, high water absorption can be expected, which creates a considerable technological 
challenge [56,57]. Further, a high radius of curvature of the nanoparticle surfaces and surface steps may induce differences in interaction energies compared with those for relatively flat microcrystalline particles [35]. To the best of our knowledge, no research into the processes of water adsorption from air by nano-hydroxyapatite as a function of particle size has been presented in the literature to date. Therefore, our results are also useful for comparing the adsorption properties of nanomaterials and their microcrystalline counterparts.

\section{Materials and Methods}

All the tests presented in this paper were performed at an accredited testing laboratory, No. AB 1503, according to the ISO 17025:2005 standard.

\subsection{Substrates}

The reagents were used in the "as received" condition: calcium hydroxide $\left(\mathrm{Ca}(\mathrm{OH})_{2}\right.$, pure); orthophosphoric acid $\left(\mathrm{H}_{3} \mathrm{PO}_{4}, 85 \mathrm{wt} \%\right.$ solution, analytically pure); sodium chloride ( $\mathrm{NaCl}$, pure). All reagents were purchased from Chempur (Piekary Sląskie, Poland). Deionized water (specific conductance $<0.1 \mathrm{~S} / \mathrm{cm}$, HLP 20UV, Hydrolab, Straszyn, Poland) was used for the synthesis and investigation of kinetics of the water vapour adsorption.

\subsection{Synthesis of Hydroxyapatite Nanoparticles}

Nano-hydroxyapatite with the trademark GoHAP ${ }^{\mathrm{TM}}$ was used. The nanoparticles of GoHAPTM hydroxyapatite used in the tests were obtained according to the procedures of the Laboratory of Nanostructures, Polish Academy of Sciences [32,48]. This method of hydroxyapatite synthesis enables control of the size of GoHAP ${ }^{\mathrm{TM}}$ nanoparticles within the range $8 \pm 2$ to $43 \pm 4 \mathrm{~nm}$. In the present work, GoHAP ${ }^{\mathrm{TM}}$ with particle sizes of 10 and $40 \mathrm{~nm}$ were examined and are referred to as GoHAP- 1 and GoHAP-6, respectively. Two methods were applied for the synthesis of GoHAP ${ }^{\mathrm{TM}}$. The hydroxyapatite sample with the particle size of $10 \mathrm{~nm}$, named GoHAP-1, was obtained with the use of the precipitation method: namely, $10.3458 \mathrm{~g}$ of $\mathrm{Ca}(\mathrm{OH})_{2}$ was poured into $450 \mathrm{~mL}$ of deionised water. Subsequently, the volume of $5.7 \mathrm{~mL}$ of $\mathrm{H}_{3} \mathrm{PO}_{4}$ was added to the water suspension of $\mathrm{Ca}(\mathrm{OH})_{2}$ by dosing the acid using a digital burette (SI Analytics, Titronic universal, TZ3260, Mainz, Germany). While adding $\mathrm{Ca}(\mathrm{OH})_{2}$ to deionised water and dosing the acid, the suspension was intensively stirred using the magnetic stirrer (SLR, SI Analytics, Mainz, Germany) at room temperature (RT). The product, i.e., water suspension of GoHAP ${ }^{\mathrm{TM}}$ nanoparticles, was obtained after 30 min of stirring. The reaction of obtaining GoHAP ${ }^{\mathrm{TM}}$ is presented in the following Equation (1).

$$
10 \mathrm{Ca}(\mathrm{OH})_{2}+6 \mathrm{H}_{3} \mathrm{PO}_{4} R T \rightarrow \mathrm{Ca}_{10}\left(\mathrm{PO}_{4}\right)_{6}(\mathrm{OH})_{2}(\downarrow)+18 \mathrm{H}_{2} \mathrm{O}
$$

The hydroxyapatite sample with the particle size of $40 \mathrm{~nm}$, referred to as GoHAP-6 in this publication, was obtained as a result of hydrothermal heating of water suspension of GoHAP- 1 in the MSS2 microwave reactor ( 3 kW, 2.45 GHz, IHPP PAS (Warsaw), ITeE-PIB (Radom), ERTEC (Wroclaw), Poland) $[58,59]$. The following parameters of the microwave hydrothermal heating were applied: power $=3 \mathrm{~kW}$, duration $=1,200$ seconds, pressure $=20$ bar (equilibrium temperature $\sim 220^{\circ} \mathrm{C}$ ). The suspensions of GoHAP ${ }^{\mathrm{TM}}$ nanoparticles after decantation were frozen rapidly using liquid nitrogen and dried in the freeze dryer (Lyovac GT-2, SRK Systemtechnik GmbH, Riedstadt, Germany).

\subsection{Measurement of Density and Specific Surface Area}

The specific surface area (SSA) of GoHAP ${ }^{\mathrm{TM}}$ was determined by the BET (Brunauer-Emmett-Teller) adsorption method, in accordance with the ISO 9277:2010 standard. The Gemini 2360 surface analyser by Micromeritics was used in the tests. The skeleton density of the samples was measured using the AccuPyc II 1340 helium pycnometer by Micromeritics, in accordance with the ISO 12154:2014 standard. Before the SSA and density measurements, the GoHAP ${ }^{\mathrm{TM}}$ was desorbed in a desorption 
station (Micromeritics, FlowPrep 06) at a temperature of $150{ }^{\circ} \mathrm{C}$ for $2.5 \mathrm{~h}$ in a helium stream. Based on the experimentally determined SSA and skeleton density, the mean diameter of GoHAPTM, also known as the Sauter mean diameter (SMD), was calculated using Equation (2), with the assumption of a spherical shape. The SMD of GoHAP-1 $(10 \mathrm{~nm})$ and GoHAP-6 $(40 \mathrm{~nm})$ are 10 and $40 \mathrm{~nm}$, respectively. Table 1 presents the SSA, skeleton density, and Sauter mean diameter of the samples.

$$
\text { Sauter mean diameter }(S M D)=\frac{A}{S S A \cdot 10^{18} \cdot \rho \cdot 10^{-21}} \quad(n m)
$$

where $S M D$ is the Sauter mean diameter of nanoparticle (nm); $A$ is a shape factor, equal to 6 for the sphere; $S S A$ is the specific surface area $\left(\mathrm{m}^{2} / \mathrm{g}\right)$; and $\rho$ is the density $\left(\mathrm{g} / \mathrm{cm}^{3}\right)$. The average pore width was calculated by the Barrett-Joyner-Halenda (BJH) method using adsorption isotherms at the $\mathrm{P} / \mathrm{P}_{0}$ range of $0.001-0.99$. The Adsorption Isotherm was determined using the helium pycnometer at the temperature of $24 \pm 1{ }^{\circ} \mathrm{C}$ (ISO 12154:2014, AccuPyc II 1340 FoamPyc V1.06, Micromeritics, Atlanta, GA, USA). The total pore volume of samples was estimated from the amount of adsorbed nitrogen at $\mathrm{P} / \mathrm{P}_{0}=0.9896$. The obtained data of the adsorption isotherms were analysed by us using the MicroActive software V4.03 (Interactive Data Analysis Software, Micromeritics). The results of pore width measurements, total pore volume measurements and adsorption isotherm can be found in the Supplementary Materials file (Figure S1, Table S1).

Table 1. GoHAP ${ }^{\mathrm{TM}}$ characterisation. Specific surface area (SSA); skeleton density (DEN); mean particle size based on BET (SMD $\mathrm{BET}_{\text {) }}$; TEM histogram of log-normal curve $\left(\mathrm{MPS}_{\mathrm{TEM}}\right)$; mean crystallite size from Nanopowder XRD Processor Demo $\left(\mathrm{MCS}_{\mathrm{XRD}}\right)$ [41,44]; Scherrer equation $\left(\mathrm{MCS}_{\mathrm{Sch}}\right)$.

\begin{tabular}{cccccccc}
\hline \multirow{2}{*}{ Sample Name } & SSA (BET) & DEN & SMD $_{\text {BET }}$ & MPS $_{\text {TEM }}$ & MCS $_{\text {XRD }}$ & \multicolumn{2}{c}{ MCS $_{\text {Sch }}$} \\
\cline { 2 - 8 } & $\left(\mathbf{m}^{2} / \mathbf{g}\right)$ & $\mathbf{( g / \mathbf { c m } ^ { 3 } )}$ & $\mathbf{( n m )}$ & $\mathbf{( n m )}$ & $\mathbf{( n m )}$ & $\begin{array}{c}\text { Length } \\
(\mathbf{n m})\end{array}$ & $\begin{array}{c}\text { Width } \\
(\mathbf{n m})\end{array}$ \\
\hline GoHAP-1 $(10 \mathrm{~nm})$ & $206 \pm 1$ & $2.87 \pm 0.01$ & 10 & - & $10 \pm 6$ & 19 & 5 \\
\hline GoHAP-6 $(40 \mathrm{~nm})$ & $49 \pm 1$ & $3.09 \pm 0.01$ & 40 & $39 \pm 1$ & $62 \pm 43$ & 54 & 34 \\
\hline
\end{tabular}

\subsection{X-Ray Powder Diffraction}

The phase purity and the crystallite size were tested by means of X-ray diffraction (XRD) using an X-ray powder diffractometer by Panalytical, model X'Pert PRO equipped with a copper anode (Cu $\mathrm{K} \alpha 1)$ and an ultra-fast PIXcel ${ }^{1 \mathrm{D}}$ detector. The analysis was performed at room temperature in the range $2 \theta=10-100^{\circ}$ with a step of $0.03^{\circ}$. The analysis of XRD line profiles was carried out using an analytical formula for polydispersed powders $[60,61]$. The Nanopowder XRD Processor Demo online tool was used. The diffraction files were placed on the website (http://science24.com/xrd/), where they were processed to extract the size distribution of crystallites. This tool solves sets of equations in several auxiliary spaces at the same time, which allows to analyse XRD data with mutually entangled peaks. Thanks to this method, information on four parameters was obtained: mean crystallite size, error of the mean size of crystallites, dispersion of sizes and error of dispersion of sizes. Therefore, the full curve of the crystallite size distribution with its errors has been presented. For reference the mean crystallite sizes of GoHAPTM were also calculated from the diffraction line widths using the conventional Scherrer method [53]. The size along the " $c$ " crystallographic axis was calculated using the (002) diffraction line and the size along the "a" axis was calculated using the (300) diffraction line.

\subsection{Morphology Characteristics}

The morphology of GoHAPTM was tested using SEM (Ultra Plus, Carl Zeiss Meditec AG, Jena, Germany) with Secondary electrons (SE) detector and TEM (FEI Talos F200X, Thermo Fisher Scientific, Waltham, MA, USA), with the beam energy of $2 \mathrm{keV}$. An amorphous carbon layer produced using the sputter coater (SCD 005/CEA 035, BAL-TEC, Balzers, Lichtenstein) was deposited on the samples 
for SEM observations. SEM images were obtained at magnifications of $25,000 \times$ and $250,000 \times$ and with electron high tension of circa $2 \mathrm{kV}$. TEM observations were carried out with diffraction contrast using two techniques: bright and dark field. In the dark field technique, nanoparticles were observed using a selected beam that was diffracted at an angle corresponding to the diffraction of electrons on the following families of planes: family $\{100\}$ of hcp structure of $\mathrm{Ca}_{10}\left(\mathrm{PO}_{4}\right)_{6}(\mathrm{OH})_{2}$ with the fixed lattice a $=9.424(4) \AA, c=6.879(4) \AA$ (space group: P63/m, 176). TEM images obtained using the dark field technique allowed us to determine a histogram of GoHAP-6 nanocrystallite size. This procedure consisted of circumscribing circles about visible crystallites, and the diameters of these circles corresponded to the highest longitudinal dimension of these crystallites. Subsequently, using the scale present in each recorded image, the crystallite size was converted to the actual value expressed in nanometres. ORIGIN PRO ver. 7.5 software was used for obtaining a histogram showing the number of crystallites with a given size. A log-normal curve was fitted to the chart and, based on the position of its maximum, the size of the most frequently occurring crystallites was given.

\subsection{Thermogravimetric Analysis}

A thermogravimetric analysis (TGA) of GoHAP-1 (10 nm) and GoHAP-6 $(40 \mathrm{~nm})$ was conducted to study desorption as a function of temperature. The measurement was divided into two stages: (1) recording the change in the mass of the sample subjected to helium flushing for $60 \mathrm{~min}$ at room temperature, and (2) recording the change in the mass of the sample heated at a rate of $5^{\circ} \mathrm{C} /$ minute to a temperature of $800^{\circ} \mathrm{C}$, also in the helium stream. The tests were performed using the Thermogravimetric Analyzer (TGA) (STA 449 F1 Jupiter, Netzsch, Selb, Deutschland). At the same time, the gases released from GoHAP ${ }^{\text {TM }}$ during the thermal treatment were analysed using the QMS 403 C Aëolo quadrupole mass spectrometer by Netzsch. The sorption properties of GoHAP-1 $(10 \mathrm{~nm})$ and of silica gel $(3-5 \mathrm{~mm})$, a typical material used for air drying, were compared. The silica gel was exposed to an ambient relative humidity of $38 \pm 2 \%$ and $58 \pm 2 \%$. The sample mass increment was recorded in situ, and the kinetic curve and the percentage mass increment after $120 \mathrm{~min}$ were determined. The results were compared with the corresponding data obtained for GoHAP-1 (10 nm).

\subsection{Measurement of Relative Humidity}

The temperature and humidity measurements were performed with the use of the Temperature and Relative Humidity Data Logger (TR300, AMPROBE, Seattle, WA, USA) with the measurement range of relative humidity (RH) from 0 to $100 \%$. The accuracy of this device is $\pm 3 \% \mathrm{RH}$ and $\pm 0.6{ }^{\circ} \mathrm{C}$, while the resolution is $0.1 \%$ of $\mathrm{RH}$ and $0.1^{\circ} \mathrm{C}$.

\subsection{Kinetics of the Water Vapour Adsorption}

Before measurement, GoHAPTM was desorbed at $150{ }^{\circ} \mathrm{C}$ for $2.5 \mathrm{~h}$ in the helium flow. Degassed samples with a repetitive mass of approximately $0.5 \mathrm{~g}$, poured loosely into vessels with the same overall dimensions, were placed on the pan of the WAA 100/C/1 (RADWAG) analytical scales. The change in the mass of GoHAPTM exposed to an ambient relative humidity of $26 \pm 2 \%$ and $38 \pm 2 \%$ (water activity: 0.26 and 0.38 , respectively) was recorded in situ; for GoHAP-1 $(10 \mathrm{~nm})$, an additional measurement was performed in the ambient relative humidity of $58 \pm 2 \%$ (water activity: 0.58 ). The temperature of all experiments was constant at $24 \pm 0.5^{\circ} \mathrm{C}$. In order to obtain a relative humidity of $26 \%$ or $38 \%$, the stable relative air humidity prevailing in a given period in the test room was used. The highest degree of relative humidity was achieved by placing a vessel containing a saturated aqueous solution of $\mathrm{NaCl}$ in a sealed desiccator cabinet with volume $109 \mathrm{~L}$. The overall dimensions of the desiccator were sufficiently large for holding the scales containing the tested sample. Each time, the tests were performed until the sample was water saturated under the given conditions. This corresponded to stabilisation of the sample mass (adsorption equilibrium). The thickness of the water layer corresponding to the saturated condition was calculated. The kinetic curves of water adsorption 
were prepared, i.e., the curves of the sample mass change as a function of time of exposure for constant relative humidity and temperature.

During the analysis of the results, we took into account that the specific surface area of GoHAP-1 $(10 \mathrm{~nm})$ was over four times greater than that of GoHAP-6 $(40 \mathrm{~nm})$. Therefore, two variants for expressing the mass increment were used to present the kinetic curves of water adsorption: (1) by percentage with reference to the initial sample mass (\%), and (2) per $1 \mathrm{~m}^{2}$ of the surface of the exposed GoHAP ${ }^{\mathrm{TM}}\left(\mathrm{mg} / \mathrm{m}^{2}\right)$. The percentage mass increment corresponding to the state of equilibrium is described as adsorption. The mass increment per one metre of the adsorbent surface achieved in the saturated condition is referred to as "specific adsorption" in this paper. Furthermore, an isotherm of water vapour adsorption on the surface of GoHAP-1 $(10 \mathrm{~nm})$ and GoHAP-6 $(40 \mathrm{~nm})$ was determined. Similarly, as with the kinetics tests, samples with a mass of about $0.5 \mathrm{~g}$ were desorbed and subsequently exposed to the ambient conditions characterised by varied water activities: $0.03,0.24,0.38,0.51,0.62$, and 0.97 . The desired relative humidity was achieved by moisturising the air adjacent to the scales ( 0.24 and 0.38$)$ or using sealed desiccators with appropriate substances placed inside them: silica gel (water activity 0.03), a saturated aqueous solution of $\mathrm{NaCl}(0.51$ and 0.62$)$, or deionised water (0.94). The samples were exposed to ambient conditions for $24 \mathrm{~h}$. This period was sufficient to achieve a state of equilibrium in each of the experiment variants. In the cases of water activity $0.24-0.62$, the change in the sample mass was recorded in situ. At the extreme conditions of the experiment (water activity 0.03 and 0.94), the samples were weighed cyclically using an external scale. The quantity of water adsorbed by GoHAPTM, corresponding to the saturated state under the given conditions, was determined. Based on the obtained results, isotherms of adsorption for GoHAP-1 $(10 \mathrm{~nm})$ and GoHAP-6 $(40 \mathrm{~nm})$ were determined, i.e., curves of change in the quantity of water adsorbed until equilibrium is reached as a function of the ambient water activity. The degree to which the experimental curve fits the BET isotherm models was checked. Based on the isotherm feature, the number of water molecule layers for the equilibrium state at a given humidity was calculated.

\section{Results}

\subsection{Material Characterisation}

The SSA of GoHAPTM of $10 \mathrm{~nm}\left(206 \pm 1 \mathrm{~m}^{2} / \mathrm{g}\right)$ is over four times greater than that of GoHAPTM of $40 \mathrm{~nm}\left(49 \pm 1 \mathrm{~m}^{2} / \mathrm{g}\right)$. Additionally, its skeleton density is nearly $10 \%$ lower: $2.87 \pm 0.01$ versus $3.09 \pm 0.01 \mathrm{~g} / \mathrm{cm}^{3}$, respectively (Table 1). We suggest that the reduced GoHAPTM density is the result of a greater fraction of the disordered surface layer of nano-hydroxyapatites in the material volume. We described the effect of the nanoparticle density decrease as a function of its SSA increase previously for the example of $\mathrm{ZrO}_{2}$ nanoparticles [62].

Figure 1 shows $\mathrm{X}$-ray diffraction line profiles for both sizes of GoHAP ${ }^{\mathrm{TM}}$. No phases other than hydroxyapatite were detected. Diffraction profiles for GoHAP ${ }^{\text {TM }}$ before and after desorption are essentially identical, which indicates that the desorption process did not impact its crystallinity. The sharper peaks of GoHAP- $6(40 \mathrm{~nm})$ demonstrate that the crystallite size of the latter is larger than that of GoHAP-1 $(10 \mathrm{~nm})$. Adsorption and desorption cycles also did not affect the Specific Surface Area and Skeletal Density of GoHAPTM nanoparticles (Table S2). 


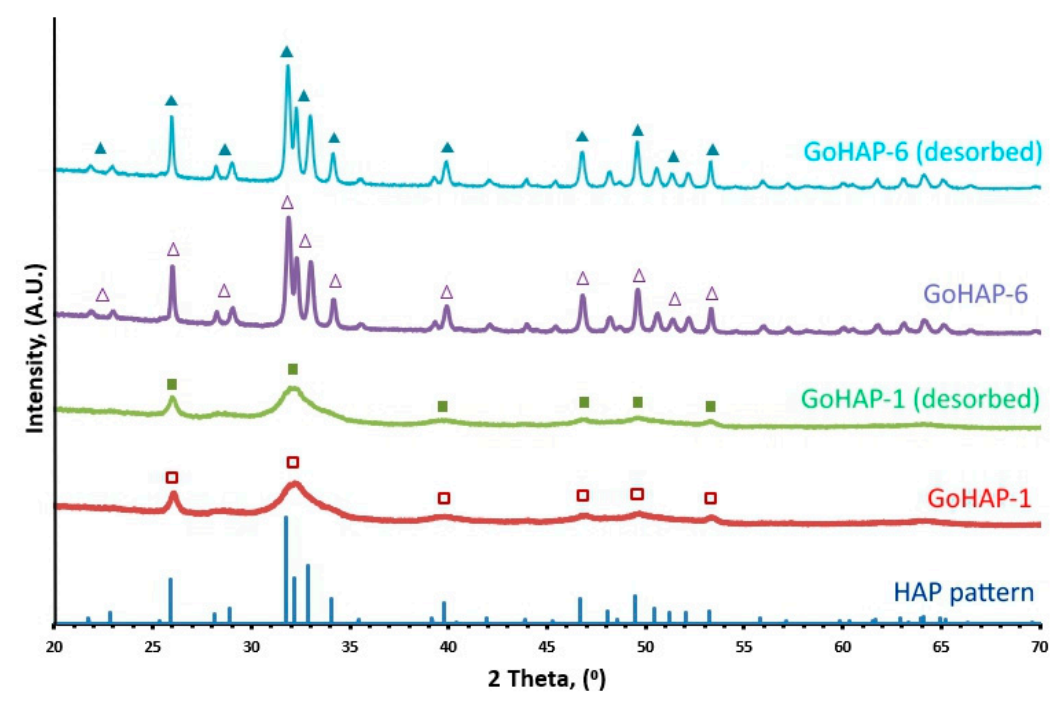

Figure 1. X-ray diffraction line profiles of $\mathrm{GoHAP}^{\mathrm{TM}}$ with particle sizes of $10 \mathrm{~nm}$ and $40 \mathrm{~nm}$ before and after desorption.

Figure 2 presents selected SEM images of GoHAPTM. Clusters of spherical objects are visible that have an estimated single constituent size of 10-15 nm for the GoHAP-1 (10 nm) powder and approximately $40 \mathrm{~nm}$ for the GoHAP-6 $(40 \mathrm{~nm})$ powder.
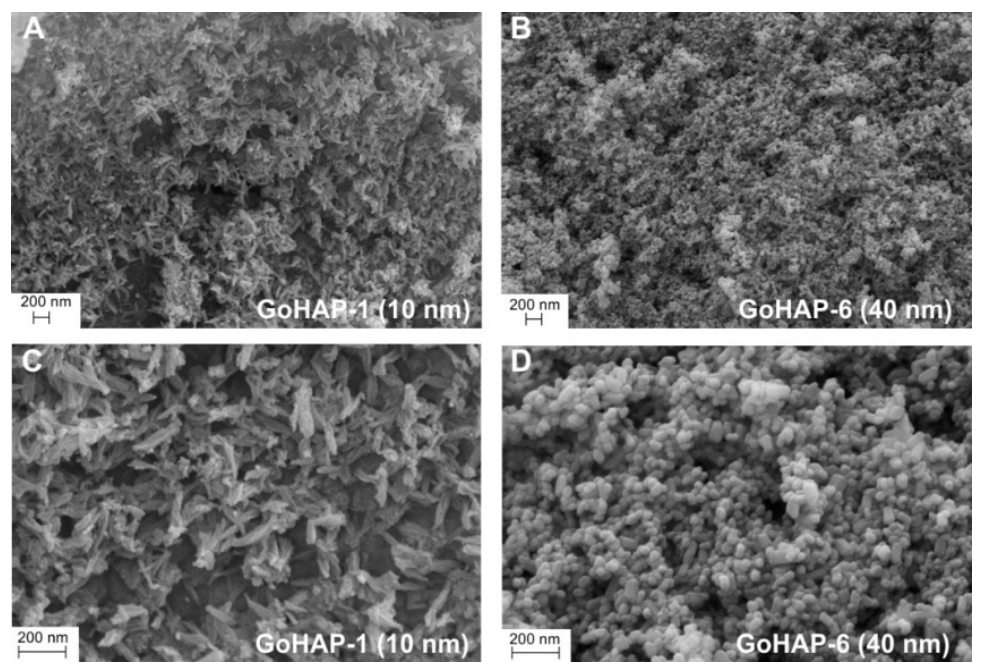

Figure 2. SEM image of GoHAP ${ }^{\mathrm{TM}}$ with different particle sizes of $10 \mathrm{~nm}(\mathbf{A}, \mathbf{C})$ and $40 \mathrm{~nm}(\mathbf{B}, \mathbf{D})$.

HR TEM images (Figure 3) obtained by the bright field technique revealed differences in the morphology of GoHAP ${ }^{\mathrm{TM}}$. GoHAP-6 $(40 \mathrm{~nm})$ has a polyhedron shape, which reflects the hexagonal crystalline structure of hydroxyapatite. TEM images made by the dark field technique enabled the determination of the GoHAP-6 (40 nm) nanoparticle size, and the mean particle size (MPS) based on a fit to the histogram of the log-normal curve is $39 \mathrm{~nm}$ (Figure 4B). This value coincides with the $40 \mathrm{~nm}$ calculated using the SSA and density parameters (SMD ${ }_{\mathrm{BET}}$, Table 1). Based on the GoHAP ${ }^{\mathrm{TM}}$ diffraction line profile analysis $[60,61]$, the mean size of the GoHAP-6 $(40 \mathrm{~nm})$ crystallites $\left(\mathrm{MCS}_{\mathrm{XRD}}\right)$ is $62 \pm 43 \mathrm{~nm}$. According to the Scherrer formula, crystallites of GoHAP-6 (40 nm) have a length of $54 \mathrm{~nm}$ and a width of $34 \mathrm{~nm}$. In the case of GoHAP-1 $(10 \mathrm{~nm})$. Due to the strong tendency to agglomerate, it was not possible to determine the GoHAP-1 $(10 \mathrm{~nm})$ mean particle size using microscopic imaging. GoHAP-1 $(10 \mathrm{~nm})$ crystallites have a length of $19 \mathrm{~nm}$ and a width of $5 \mathrm{~nm}$. An analysis of the GoHAPTM diffraction line profile $[60,61]$ revealed that the mean size of the crystallite $\left(\mathrm{MCS}_{\mathrm{XRD}}\right)$ GoHAP-1 $(10 \mathrm{~nm})$ 
was $10 \pm 6 \mathrm{~nm}$. Table 1 presents a summary of the quantitative nanoparticle characterisation. The obtained results confirmed the previously reported particle size and shape differences between the two types of GoHAPTM [32].
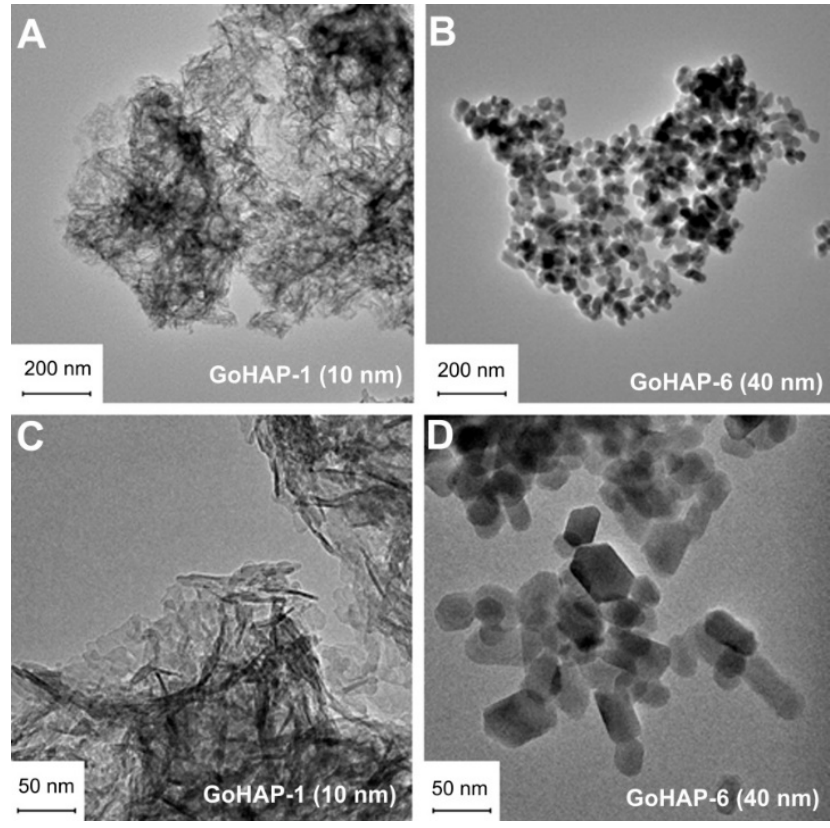

Figure 3. HR TEM image of GoHAP ${ }^{\mathrm{TM}}$ with different particle sizes of $10 \mathrm{~nm}(\mathbf{A}, \mathbf{C})$ and $40 \mathrm{~nm}(\mathbf{B}, \mathbf{D})$.

A

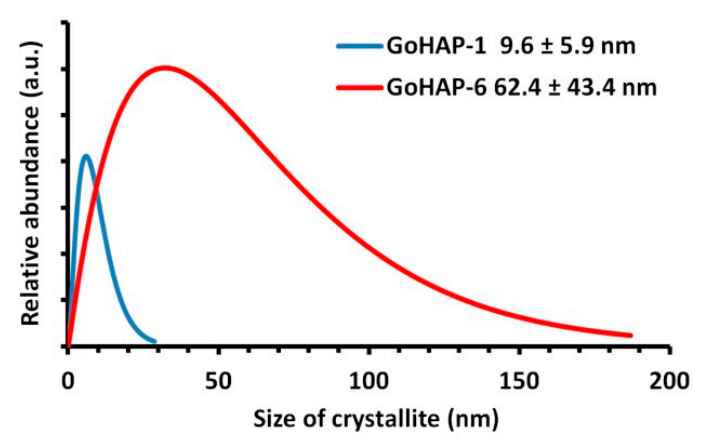

B

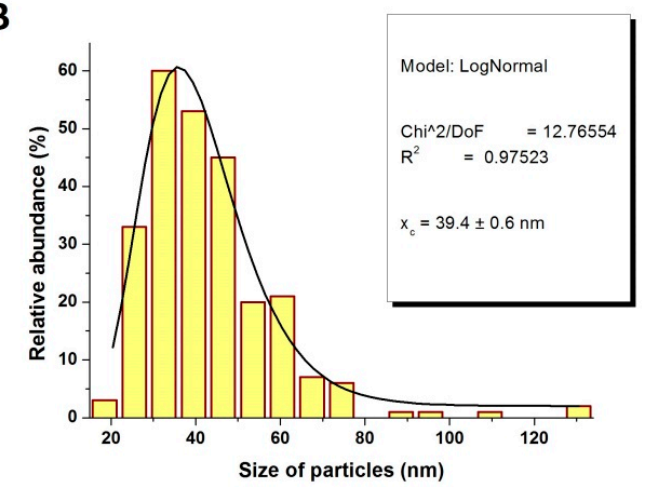

Figure 4. Crystallite size distribution (A) based on analysis of the fine structure of the X-ray diffraction line profiles, (B) obtained from HR TEM observations.

\subsection{Examination of Water Adsorption Process}

Regardless of the experimental conditions, the kinetic curves of water adsorption from air by GoHAPTM have a similar shape and are composed of three sequential stages: (1) a rapid, nearly linear mass growth; (2) a gradually inhibited process; and (3) the state of equilibrium and stabilised sample mass. The saturated condition is reached no longer than $200 \mathrm{~min}$ after the beginning measurement. Over $50 \%$ of the equilibrium water mass is adsorbed during the initial $10 \mathrm{~min}$ of exposure. The results of adsorption kinetics tests are summarised in Table 2, and the curves obtained for GoHAP-1 (10 nm) and GoHAP-6 ( $40 \mathrm{~nm}$ ) for the ambient relative humidity of $26 \pm 2 \%$ are presented in Figure 5 . The set of curves recorded for GoHAP-1 $(10 \mathrm{~nm})$ at three different experimental conditions (water activity: $0.26,0.38$, and 0.58 ) are presented in Figure 5. 
Table 2. Impact of ambient relative humidity on the change in mass of GoHAP-1 (10 nm) samples.

\begin{tabular}{ccc}
\hline Relative Humidity (\%) & Adsorption (\%) & Specific Adsorption $\left(\mathbf{m g} / \mathbf{m}^{\mathbf{2}}\right)$ \\
\hline 26 & 5.2 & 0.25 \\
\hline 38 & 5.4 & 0.26 \\
\hline 58 & 8.2 & 0.40 \\
\hline
\end{tabular}
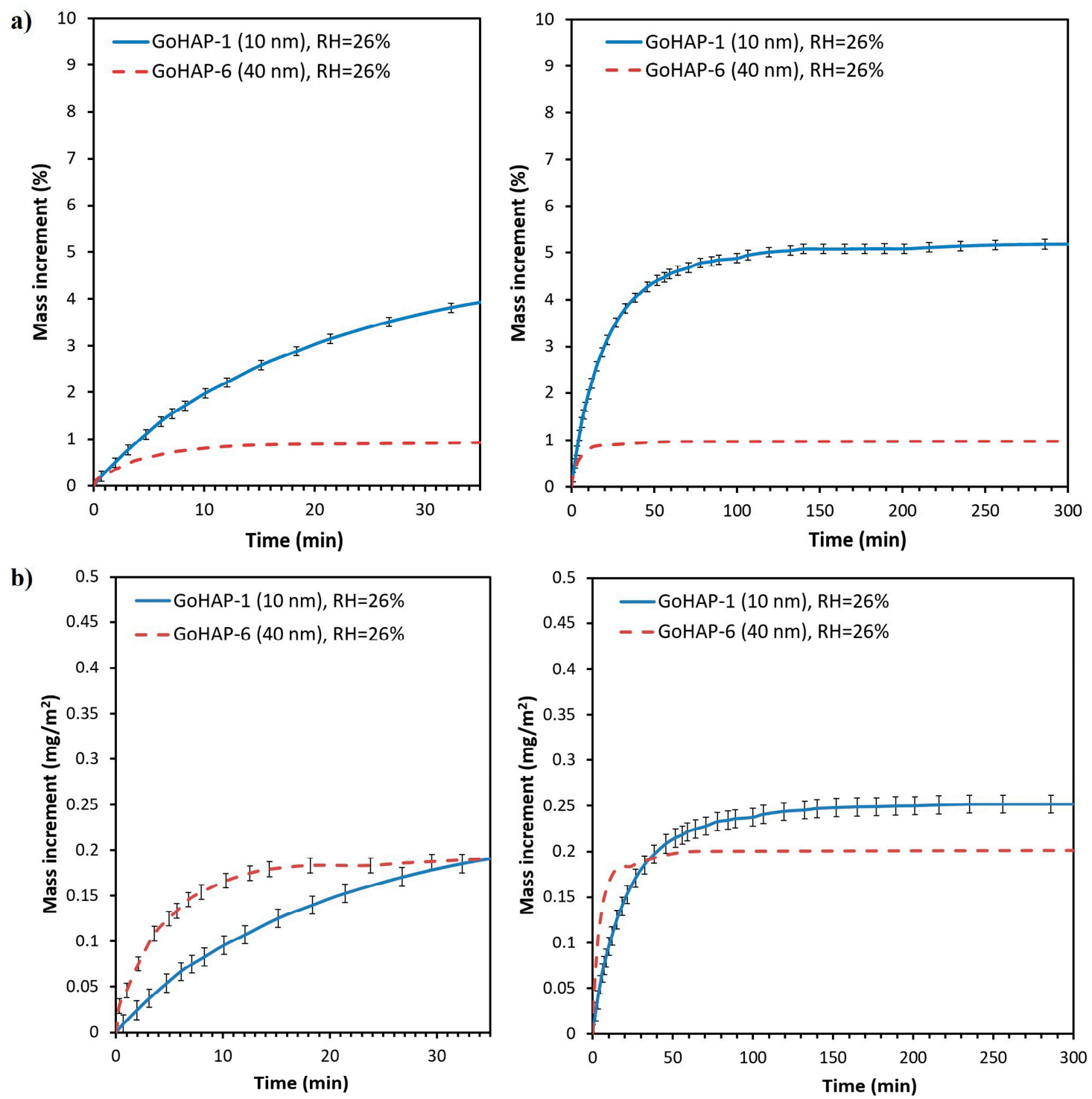

Figure 5. Kinetic curves of water adsorption on GoHAP-1 $(10 \mathrm{~nm})$ and GoHAP-6 (40 nm) with an ambient relative humidity of 26\%: (a) percentage mass change, (b) mass increment per $1 \mathrm{~m}^{2}$ of GoHAPTM.

With an ambient water activity of 0.26 , Figure 5 shows that the equilibrium increment of the GoHAP-1 (10 nm) mass is five times higher than that of GoHAP-6 (40 nm) $(5.2 \%$ and 1\%, respectively). This result is correlated with the more than fourfold difference between the total surface areas of the tested samples (see Table 1). The values of the specific adsorption of GoHAPTM, in turn, differ to a slight extent and are 0.25 and $0.21 \mathrm{mg} / \mathrm{m}^{2}$, respectively.

Regarding the impact of the water activity on the kinetics of adsorption, in the case of GoHAP-1 $(10 \mathrm{~nm})$, no difference was observed during the initial $10 \mathrm{~min}$ of exposure for a relative humidity of $26 \%$ and $38 \%$. After that period at the ambient relative humidity of $38 \%$, the mass increase is faster than for 
a relative humidity of $26 \%$ and reaches a state of equilibrium after $70 \mathrm{~min}$. The saturated condition for the relative humidity of $26 \%$ is reached after $140 \mathrm{~min}$. Despite differences in the adsorption kinetics, the quantity of water adsorbed by GoHAP-1 $(10 \mathrm{~nm})$ at the ambient relative humidity of $26 \%$ and $38 \%$ is similar and reaches slightly above $5 \%$ (Figure 6). At the ambient relative humidity of $58 \%$, in turn, the water adsorption rate for the two initial stages of the process is considerably faster than at the lower relative humidity. Adsorption at the ambient relative humidity of $58 \%$ is $8.2 \%$, e.g., 1.5 times higher than for $26 \%$ and $38 \%$ relative humidity. In other units for the surface, for a relative humidity of $58 \%, 0.4 \mathrm{mg}$ of $\mathrm{H}_{2} \mathrm{O}$ is bound to $1 \mathrm{~m}^{2}$ on the GoHAPтм surface, while for $26 \%$ and $38 \%$ humidity, the value is about $0.25 \mathrm{mg}$ of $\mathrm{H}_{2} \mathrm{O} / \mathrm{m}^{2}$.
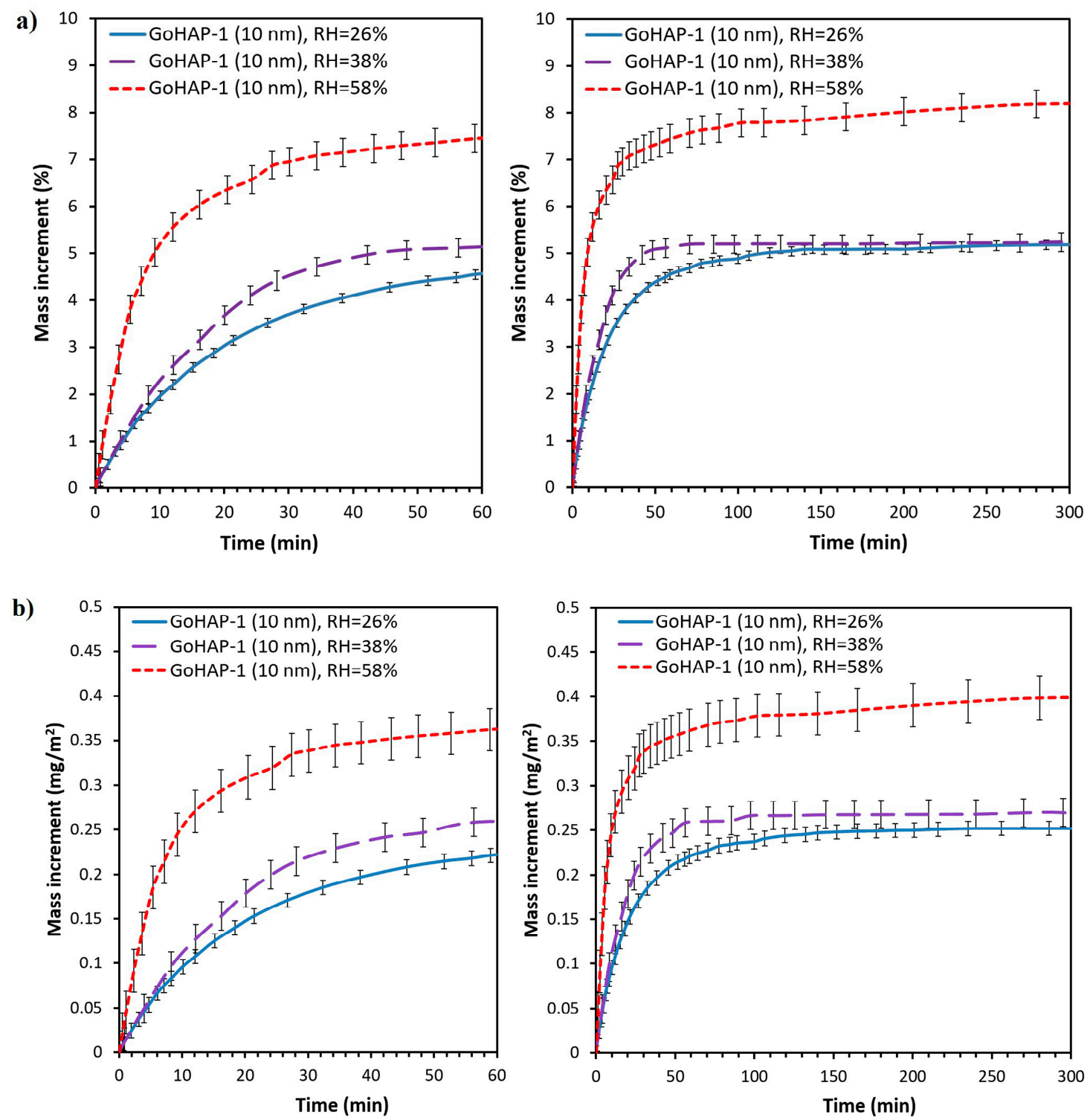

Figure 6. Kinetic curves of water adsorption on GoHAP-1 $(10 \mathrm{~nm})$ with varied ambient relative humidity values: (a) percentage mass change, (b) mass increment per $1 \mathrm{~m}^{2}$.

The kinetics of water adsorption of GoHAP ${ }^{\mathrm{TM}}$ was compared with a reference sample of silica gel. Samples were exposed for $2 \mathrm{~h}$ to the ambient relative humidity of $38 \pm 2 \%$ and $58 \pm 2 \%$ (Figure 7). 

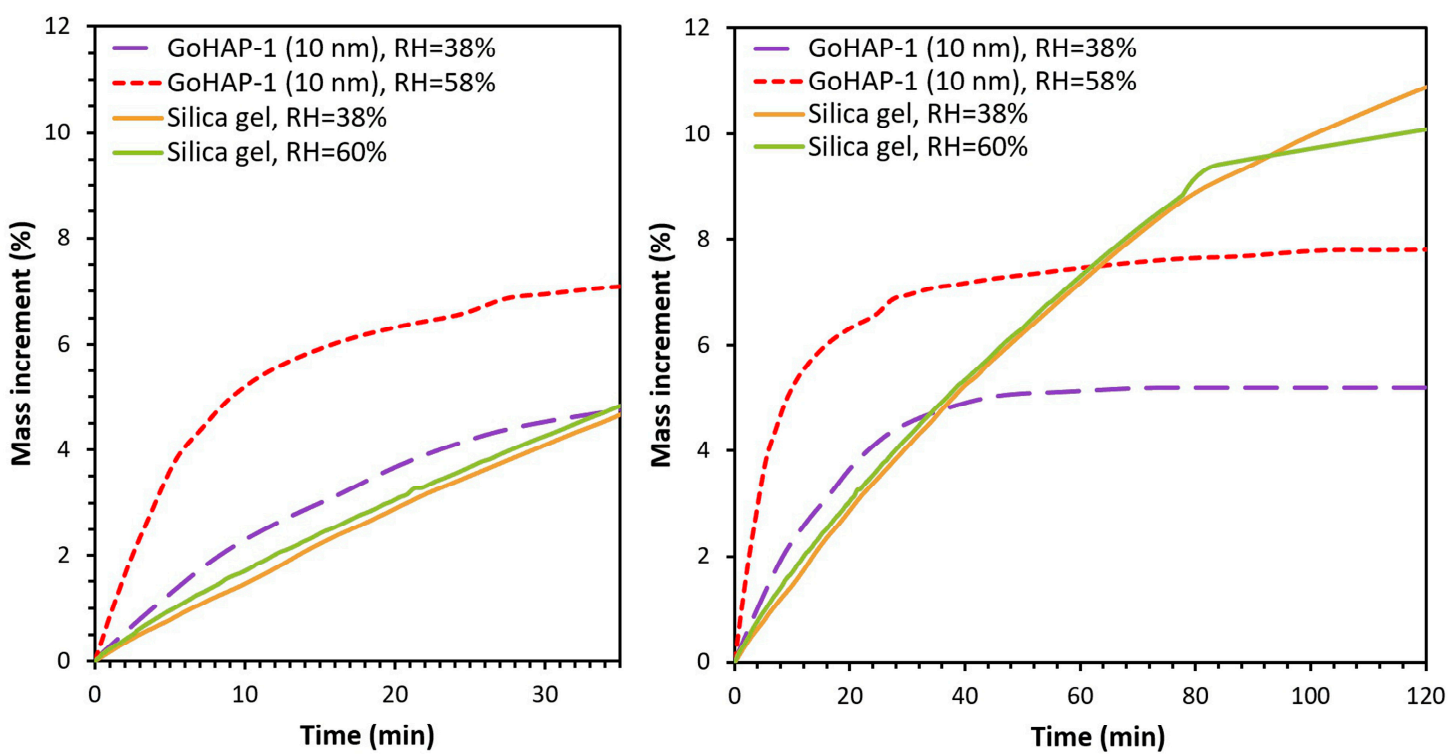

Figure 7. Kinetic curves of water adsorption on GoHAP-1 (10 nm) and Silica gel.

The silica gel mass did not stabilise within the duration of the experiment, and after two hours of adsorption, it increased by $10-11 \%$. The adsorption rate of the silica gel was the same for both ambient water activity values. The experiment indicated that, at the first stage of the process during the initial 30 min of exposure, GoHAP-1 (10 nm) was characterised by a considerably higher activity compared to silica gel. This result is significant because it shows that GoHAP-1 (10 nm) not only has very good sorption properties, but also can be a more effective and competitive sorbent than silica gel if there is a need to rapidly reduce the relative air humidity.

Based on the results of kinetic tests, an isotherm of water vapour adsorption on GoHAP-1 (10 nm) and GoHAP-6 $(40 \mathrm{~nm})$ was determined. Figure 8 presents the isotherm expressed as a change in the relative increment of GoHAPTM mass as a function of water activity. The experimental curve was compared with the isotherm models described in the relevant literature. It was found that the nature of the adsorption isotherm was consistent with the Brunauer-Emmet-Teller (BET) isotherm model [63,64], described by Equation (3):

$$
a=\frac{a_{m} C \frac{p}{p_{0}}}{\left(1-\frac{p}{p_{0}}\right)\left[1+(C-1) \frac{p}{p_{0}}\right]}
$$

where: $a$ is the total volume of adsorbed gas under pressure $p\left(\mathrm{~g} \mathrm{H}_{2} \mathrm{O} / \mathrm{g}\right.$ GoHAP); $p_{0}$ is the pressure of the adsorbate's saturated vapour $(\mathrm{Pa}) ; a_{m}$ is the volume of the monolayer $\left(\mathrm{g} \mathrm{H}_{2} \mathrm{O} / \mathrm{g} \mathrm{GoHAP}\right) ; C$ is the adsorption equilibrium constant; and $p / p_{0}=a_{w}$ is the water activity. 


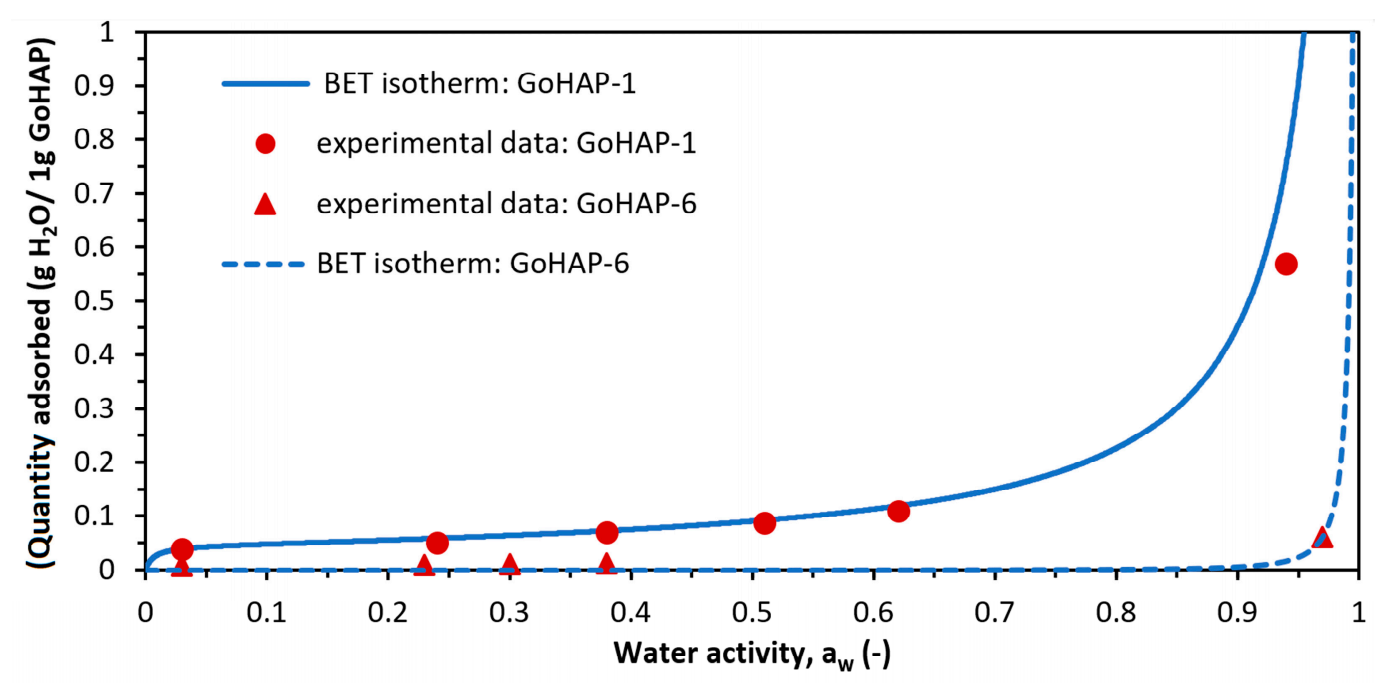

Figure 8. Brunauer-Emmett-Teller (BET) isotherm determined for water adsorption on the surface of GoHAP-1 (10 nm) and GoHAP-6 (40 nm).

The parameters for fitting the BET adsorption isotherm to the experimental data were determined (Figure 8, Table 3). However, the equation for this isotherm best fits the low range of pressures.

Table 3. Parameters of BET isotherm of water adsorption on the surface of GoHAP-1 (10 nm) and GoHAP-6 (40 nm). The volume of the monolayer $\left(\mathrm{a}_{\mathrm{m}}\left(\mathrm{g} \mathrm{H}_{2} \mathrm{O} / \mathrm{g} \mathrm{GoHAP}\right)\right)$; the adsorption equilibrium constant (C); standard deviation (S); Fisher Test (F-test).

\begin{tabular}{ccccc}
\hline \multirow{2}{*}{ Test Sample } & \multicolumn{2}{c}{ Parameter } & \multicolumn{2}{c}{ Statistics } \\
\cline { 2 - 5 } & $\mathbf{a}_{\mathbf{m}}$ & $\mathbf{c}$ & $\mathbf{S}$ & F-Test \\
\hline GoHAP-1 $(10 \mathrm{~nm})$ & 0.045 & 161 & 0.013 & 230 \\
\hline GoHAP-6 $(40 \mathrm{~nm})$ & 0.0078 & 0.00419 & 0.011 & 3.72 \\
\hline
\end{tabular}

The GoHAP ${ }^{\mathrm{TM}}$ adsorption isotherm is characteristic of type III isotherms according to Brunauer's classification [64]. This implies that hydrogen bonds are formed between the adsorbent (GoHAP'M) and the adsorbate (water) that are stronger than intermolecular interactions such as van der Waals forces. The isotherm type also suggests that a multilayer adsorption process occurs on the GoHAPтм surface. The parameter am (Table 3) corresponds to a capacity of one layer of water molecules adsorbed per 1 gram of GoHAP ${ }^{\mathrm{TM}}$. Therefore, knowledge of the am value is needed to calculate the number of water layers under given conditions.

The thickness of the water layer adsorbed on a GoHAP- 1 surface was determined after exposure for $20 \mathrm{~h}$ to air with a relative humidity of 3\%, 24\%, 38\%, 51\%, 62\%, and 94\% (Table 4). For GoHAP-6 $(40 \mathrm{~nm})$, the thickness of the water layer was revealed for a relative humidity of $3 \%, 13 \%, 24 \%, 30 \%$, $38 \%$, and $97 \%$ and an exposure time of $20 \mathrm{~h}$ (Table 5). The monolayer water coverage was calculated both by the SSA method of the HA sample $[29,31]$ and by using moisture sorption isotherm data (Figure 8) fitted to the modified BET equation. The mass of one water molecule is $2.99 \cdot 10^{-23} \mathrm{~g}$, and the cross-sectional area of a water molecule must take into account the packing density between water molecules and the hydroxyapatite surface. The cross-sectional area for the adsorption of a water molecule onto the surface of HAP has previously been reported as $0.115 \mathrm{~nm}^{2}$ [29]. 
Table 4. Estimated water layer thickness and number of monolayers of $\mathrm{H}_{2} \mathrm{O}$ molecules $\left(\mathrm{n}_{\mathrm{H} 2 \mathrm{O}}\right)$ and mean water layer thickness $\left(\mathrm{h}_{\mathrm{H} 2 \mathrm{O}}\right)$ adsorbed on the surface of GoHAP-1 $(10 \mathrm{~nm})$, depending on experimental conditions and an exposure time of $20 \mathrm{~h}$.

\begin{tabular}{ccccc}
\hline \multirow{2}{*}{ Relative Humidity } & \multicolumn{2}{c}{$h_{\mathrm{H}_{2} \mathrm{O}}(\mathbf{n m})$} & \multicolumn{2}{c}{$n_{\mathrm{H}_{2} \mathrm{O}}$} \\
\cline { 2 - 5 } & from SSA Method & from BET Isotherm & from SSA Method & from BET Isotherm \\
\hline $3 \%$ & 0.5 & 0.3 & 1.5 & 0.9 \\
\hline $24 \%$ & 1.1 & 0.3 & 3.8 & 1.6 \\
\hline $38 \%$ & 1.2 & 0.6 & 4.1 & 2 \\
\hline $62 \%$ & 1.3 & 0.9 & 4.4 & 3 \\
\hline $94 \%$ & 7.1 & 3.6 & 23.6 & 12 \\
\hline
\end{tabular}

Table 5. Water layer thickness and number of monolayers of $\mathrm{H}_{2} \mathrm{O}$ molecules adsorbed on the surface of GoHAP-6 (40 nm), depending on the experimental conditions and an exposure time of $20 \mathrm{~h}$.

\begin{tabular}{ccccc}
\hline \multirow{2}{*}{ Relative Humidity } & \multicolumn{3}{c}{$h_{\mathrm{H}_{2} \mathrm{O}}(\mathbf{n m})$} & \multicolumn{2}{c}{$n_{\mathrm{H}_{2} \mathrm{O}}$} \\
\cline { 2 - 5 } & from SSA Method & from BET Isotherm & from SSA Method & from BET Isotherm \\
\hline $3 \%$ & 0.2 & 0.3 & 0.6 & 1.0 \\
\hline $24 \%$ & 0.2 & 0.4 & 0.7 & 1.2 \\
\hline $30 \%$ & 0.3 & 0.5 & 0.9 & 1.5 \\
\hline $38 \%$ & 0.3 & 0.5 & 1.0 & 1.6 \\
\hline $97 \%$ & 1.4 & 2.3 & 4.8 & 7.8 \\
\hline
\end{tabular}

The monolayer coating calculated using the modified BET method was lower than that calculated using the surface area approach, similar to calculations [31] for granulated hydroxyapatite. According to the authors of Reference [31], the BET approach will probably underestimate the true coverage of the monolayer, and it can be assumed that a specific approach to the surface can provide a more accurate determination of the monolayer coverage. Therefore, the number of water layers was calculated by dividing the humidity sample content by the monolayer water coverage of $0.2605 \mathrm{mg} / \mathrm{m}^{2}$ [29]. The calculation included the packing efficiency of 0.74 [65].

The results of a thermogravimetric analysis coupled with differential scanning calorimetry of GoHAP ${ }^{\mathrm{TM}}$ are presented in Figure 9. The thermogravimetric (TG) curve reflects the changes in the mass of the sample as a function of temperature. The calorimetry curve (DSC) reflects the heat flow corresponding to the processes occurring in the sample. Mass spectrometry results, presenting ion currents of $\mathrm{H}_{2} \mathrm{O}(\mathrm{m} / \mathrm{z}=18)$ and $\mathrm{CO}_{2}(\mathrm{~m} / \mathrm{z}=44)$ in gases released from samples during the TG experiment, are shown in Figure 8. In addition, derivatives of the thermogravimetric curves (DTG) are drawn in Figure 10 to allow a comparison between the analysed ion current changes and the mass changes in the samples.

a)

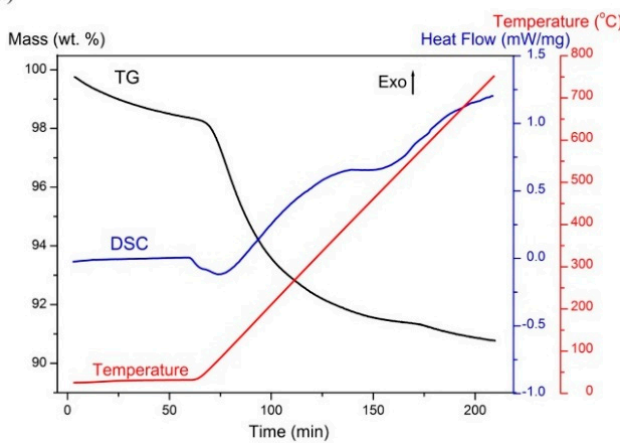

b)

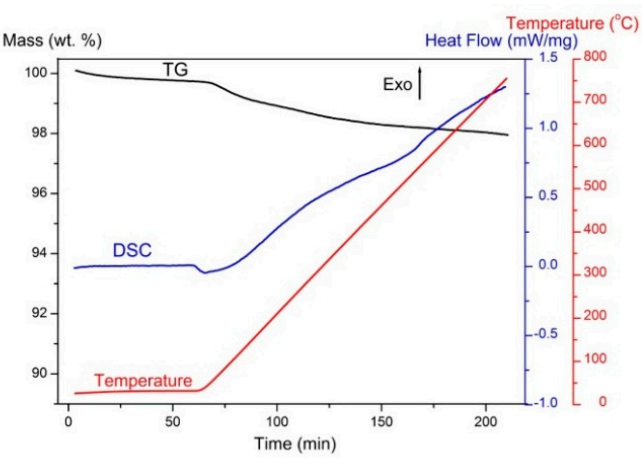

Figure 9. Thermogravimetry (TG) and calorimetry (DSC) curves of (a) GoHAP-1 (10 nm) and (b) GoHAP-6 $(40 \mathrm{~nm})$ soaked up to $800^{\circ} \mathrm{C}$. The temperature change as a function of time is also presented. 
a)

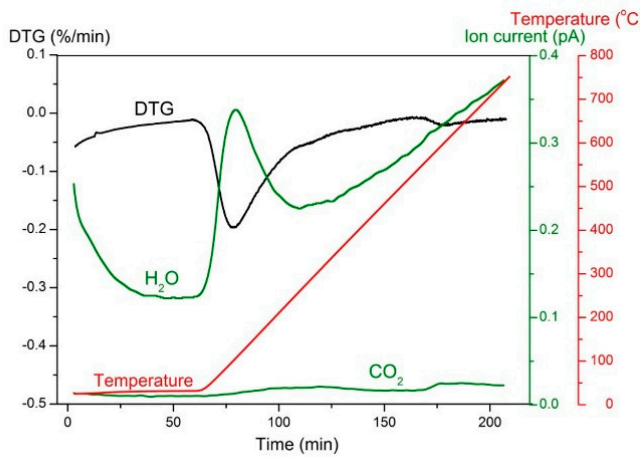

b)

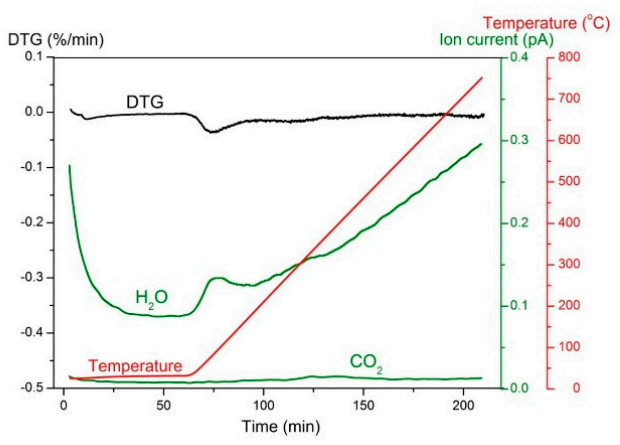

Figure 10. $\mathrm{H}_{2} \mathrm{O}$ and $\mathrm{CO}_{2}$ ion currents and derivative thermogravimetric (DTG) curves of (a) GoHAP-1 $(10 \mathrm{~nm})$ and $(\mathbf{b})$ GoHAP-6 $(40 \mathrm{~nm})$ soaked up to $800{ }^{\circ} \mathrm{C}$. The temperature change as a function of time is also presented.

A sample mass decrease was observed throughout the entire TG experiments. During the isothermal stage at room temperature, the nanoparticle surface was cleaned just as a result of helium flushing. A significant acceleration in the mass change occurs after the beginning of the heating stage. The highest speed of mass loss (seen as a peak on the DTG curve), correlating with an increase in water desorption (reflected as a peak on the $\mathrm{H}_{2} \mathrm{O}$ line), was recorded after $10 \mathrm{~min}$ of heating. Intense water desorption occurred up to approximately $150{ }^{\circ} \mathrm{C}$. This is a $150{ }^{\circ} \mathrm{C}$ lower temperature than the desorption temperature of microcrystalline hydroxyapatite proposed by Holmes et al. [30]. According to Reference [32], structural water is removed from GoHAP ${ }^{\text {TM }}$ in the temperature range $200{ }^{\circ} \mathrm{C}$ to $600{ }^{\circ} \mathrm{C}$. In the present work, this phenomenon overlaps with the removal of $\mathrm{CO}_{2}$ molecules from hydroxyapatite, resulting in a slight increase of the ionic current value (Figure 10). The sum of both processes was reflected as a small peak on the DTG curve of GoHAP-1 $(10 \mathrm{~nm})$ and is more intense on the DSC curves for GoHAP-1 (10 nm) and GoHAP-6 (40 nm) (Figures 9 and 10).

Thermal analysis coupled with mass spectroscopy of both hydroxyapatite sizes showed that the recorded mass loss results mostly from dehydration. However, it also clearly revealed significant differences between the rate and effectiveness of water desorption depending on nanoparticle size. While flushing the GoHAP-1 $(10 \mathrm{~nm})$ with helium at room temperature for $1 \mathrm{~h}$, the mass loss was $1.64 \mathrm{wt} \%$. The weight loss resulting from heating to $800{ }^{\circ} \mathrm{C}$ was $7.59 \mathrm{wt} \%$. In total, the GoHAP-1 $(10 \mathrm{~nm})$ mass loss was $9.23 \mathrm{wt} \%$. For GoHAP-6 $(40 \mathrm{~nm})$, the helium flush stage resulted in a mass loss of $0.26 \%$, and heating the sample to $800{ }^{\circ} \mathrm{C}$ resulted in $1.78 \%$ of the mass being lost. In total, the mass of GoHAP-6 $(40 \mathrm{~nm})$ decreased by $2.04 \%$. Mass changes during the TG process are similar to those obtained in the desorption station as a result of heating for $2.5 \mathrm{~h}$ at $150{ }^{\circ} \mathrm{C}$ and flushing with helium (Table 6). This demonstrates that an appropriate selection of the sample desorption conditions leads to nearly total degassing of GoHAP ${ }^{\mathrm{TM}}$ without high temperature treatment.

Table 6. Mass changes in GoHAP ${ }^{\mathrm{TM}}$ during thermogravimetric analysis (TG) and in the desorption station (DS).

\begin{tabular}{ccc}
\hline \multirow{2}{*}{ Sample Name } & \multicolumn{2}{c}{ Mass Change (\%) } \\
\cline { 2 - 3 } & Heating to $\mathbf{8 0 0}{ }^{\circ} \mathbf{C}(\mathrm{TG})$ & Heating to $\mathbf{1 5 0}{ }^{\circ} \mathbf{C}(\mathrm{DS})$ \\
\hline GoHAP-1 $(10 \mathrm{~nm})$ & -9.2 & -6.3 \\
\hline GoHAP-6 $(40 \mathrm{~nm})$ & -2.0 & -1.8 \\
\hline
\end{tabular}

\section{Discussion}

The mechanism of water binding by $10 \mathrm{~nm}$ nano-hydroxyapatite, $40 \mathrm{~nm}$ nano-hydroxyapatite, and microcrystalline hydroxyapatite [30] is the same regardless of the particle size. However, the size of hydroxyapatite affect the amount of adsorbed water. With a relative humidity between 3-97\%, 
many more layers/molecules of water are adsorbed on the surface of $10 \mathrm{~nm}$ GoHAPтм than $40 \mathrm{~nm}$ GoHAP ${ }^{\mathrm{TM}}$. The greater increment in the $10 \mathrm{~nm}$ GoHAP ${ }^{\mathrm{TM}}$ mass is probably caused by two factors: (1) the higher availability of the surface that water molecules can directly attach to, and (2) the larger number of monolayers. Nanoparticles have a large ratio of surface area to mass. Nanoparticles with dimensions of several $\mathrm{nm}$ are composed largely of surface atoms and contribution of surface energy to their total free energy is high [66]. An increase of diameter reduces the contribution of surface energy to the total energy and this is the driving force for adsorption of several monolayers of water. This explains why the $10 \mathrm{~nm}$ particles absorb more monolayers of water than the $40 \mathrm{~nm}$ ones (Figure 11). Therefore, the shape and size of GoHAPTM determine the amount of water adsorbed on the surface. The deposition of the first water layer on the surface of GoHAPтм begins at places where free $\mathrm{OH}$ groups are present on the surface of the crystals. The molecules of the first layer of water are strongly bound to the surfaces of nano-, micro- [28,29], and natural [28-30] hydroxyapatite by means of hydrogen bonds formed between hydroxy groups of hydroxyapatite and water molecules. Subsequent layers are attached by cohesion forces due to the formation of weak hydrogen bonds between water molecules. With subsequent layers of the water molecule, the Sauther mean diameter of the individual particles increases and the specific surface area decreases. The Sauter mean diameter is increased until a critical value is attained for further attachment of the water molecule layers under given ambient conditions. It can also be assumed that the amount of adsorbed water is limited because the water layers of the nano-hydroxyapatite start to contact at larger Sauther diameter, further decreasing the specific surface area available for water adsorption.

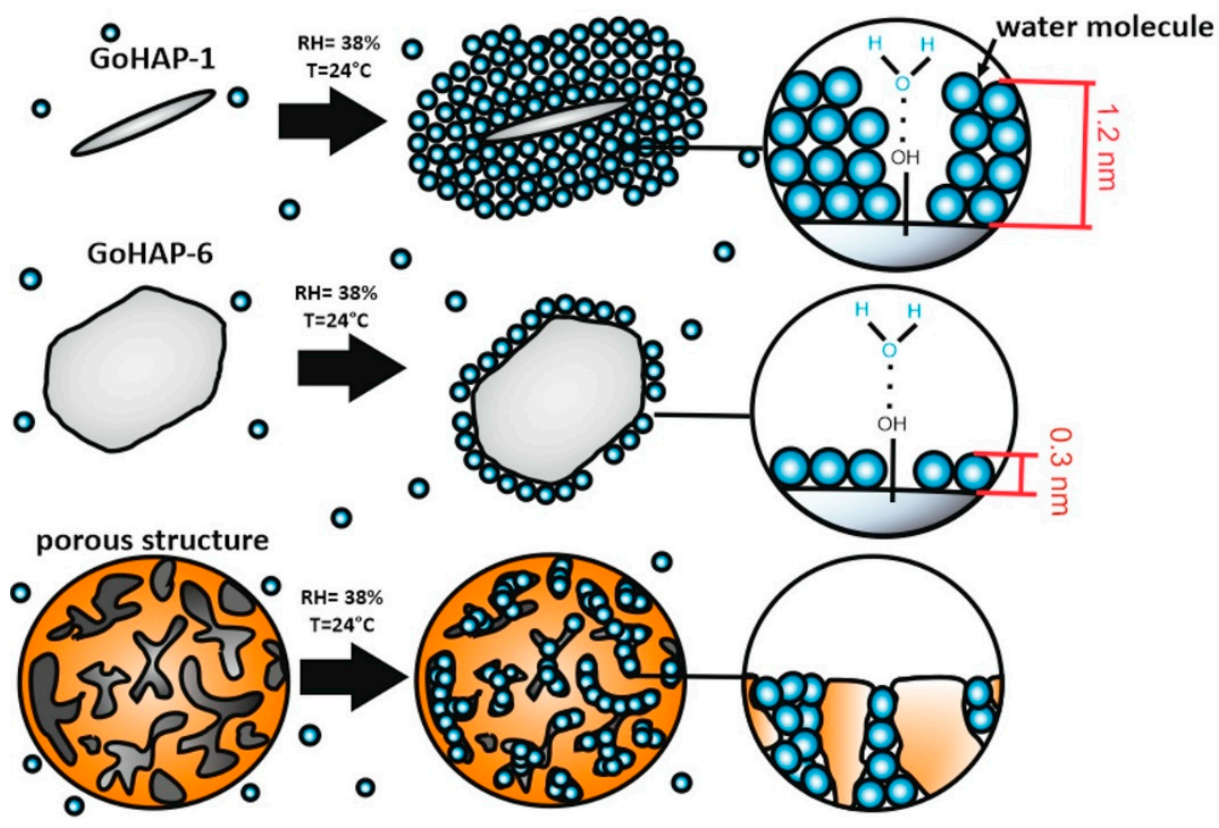

Figure 11. Nanoparticle size and shape effect on water adsorption.

The state of dispersion of hydroxyapatite can also affect the adsorption process. The studies presented earlier [31] state that the amount of water adsorbed by HAP granulate with a specific surface area of $60 \mathrm{~m}^{2} / \mathrm{g}$ is $5.26 \%$ at $25{ }^{\circ} \mathrm{C}$ and $\mathrm{RH}=30 \%$. This result is similar to the amount of water adsorbed by loosely scattered GoHAPтм with a specific surface area of $206 \mathrm{~m}^{2} / \mathrm{g}$ under similar ambient conditions. Such results may indicate a high porosity of the granules. Considering this, it can be assumed that water molecules are not only adsorbed on the surface of granular hydroxyapatite, but also that most of them are trapped in pores of granules formed between individual HAP particles. However, the rates of adsorption on the surface of loosely scattered HAP.

A comparison shows that water adsorption on the surface of $10 \mathrm{~nm}$ GoHAPTM is faster than that for silica gel granules. The rate of water adsorption by $10 \mathrm{~nm}$ GoHAPTM nanoparticles is the highest 
during the first $30-50 \mathrm{~min}$ of contact with air at $23{ }^{\circ} \mathrm{C}$ and at relative humidity levels of $38 \%$ and $58 \%$, respectively (Figure 7). GoHAP ${ }^{\mathrm{TM}}$ nanoparticles connect with water faster from the environment and reach equilibrium faster. The higher the air humidity, the higher the GoHAPTM adsorption rate. Meanwhile, silica gel granules bind water at a constant rate regardless of the humidity level, and their saturation occurs later. Silica gel adsorbs water more slowly, despite higher surface development compared to $10 \mathrm{~nm}$ GoHAPTM particles. Presumably water molecules must reach the inside of the pores of the silica gel, which slows the water adsorption process in relation to the adsorption on the surface of the loosely spilled particles. Despite the slower course of the adsorption process, the final amount of adsorbed water is higher for silica gel granules.

These results are important for applications. The relationship between the size of nano-hydroxyapatite and the amount of adsorbed water allows the water content in the material to be regulated, by adjusting the ambient humidity, exposure time and nanoparticles size. There are many applications in which a few percent difference in water content is crucial for material properties. For example, ibuprofen tablets have a maximum tensile strength at a water content of about $2.5 \%$, but this is significantly reduced at a water content of $10 \mathrm{wt} \%$ [44]. A similar change in material properties under the influence of moisture content was observed for anhydrous dextrose-an increase in water content from 0.34 to $8.9 \mathrm{wt} \%$ resulted in an increase in the tensile strength of the tablet, whereas a water content exceeding $9.2 \mathrm{wt} \%$ resulted in a significant reduction in tensile strength [67]. For this reason, the choice of nano-hydroxyapatite for specific applications should consider the particle size, as this significantly affects the amount of adsorbed water in the mass of material. Another factor influencing the water content on the surface of nano-hydroxyapatite is the relative humidity of the air. Therefore, the user of nano-HAP should pay special attention to handling and storage conditions.

\section{Conclusions}

Water adsorption and desorption by hydroxyapatite were tested as a function of nanoparticle size and the ambient relative air humidity. Two types of hydroxyapatite nanopowders obtained by microwave hydrothermal synthesis were tested. The mean nanoparticle sizes were 10 and $40 \mathrm{~nm}$, and the specific surface areas were $206 \mathrm{~m}^{2} / \mathrm{g}$ and $49 \mathrm{~m}^{2} / \mathrm{g}$, respectively.

Nanoparticle size has a strong effect on the kinetics and efficiency of water adsorption. For the same value of water activity in air, the quantity of water adsorbed on the surface of $10 \mathrm{~nm}$ hydroxyapatite was five times greater than that adsorbed on the $40 \mathrm{~nm}$ particles. It was found that the multilayer physical adsorption mechanism was active. The number of $\mathrm{H}_{2} \mathrm{O}$ molecules layers adsorbed depended on air humidity and particles size. For $10 \mathrm{~nm}$ particles it ranged from 1.5 to 23.6 monolayers for water activity in the range $0.03-0.94$. For particles of $40 \mathrm{~nm}$ size, it ranged from 0.6 to 4.8 monolayers in the same humidity range. The $10 \mathrm{~nm}$ needle-shaped particles have water adsorption properties comparable with silica gel. During the initial 30 min of sample contact with humid air, the water adsorption of $10 \mathrm{~nm}$ hydroxyapatite was even more effective than it is for silica gel. Saturation of water adsorption was observed after approximately $100 \mathrm{~min}$ of contact between the nanoparticles and air, regardless of the humidity level.

These findings are important for optimising the processing of hydroxyapatite and other nanoparticles in environment of varying humidity.

Supplementary Materials: The following are available online at http://www.mdpi.com/2079-4991/9/7/1005/s1, Figure S1: Nitrogen adsorption isotherms of GoHAP ${ }^{\mathrm{TM}}$. STP means standard temperature and pressure; Table S1: Characteristics of GoHAP ${ }^{\mathrm{TM}}$ samples; Table S2: Characteristics of GoHAPTM samples.

Author Contributions: Conceptualization, U.S. and A.Ś.-Ś.; investigation, U.S., A.Ś.Ś, A.C., S.G.; writing—original draft preparation, U.S.; writing—review and editing, A.Ś-Ś., W.Ł. and U.S.; formal analysis, U.S.; supervision, A.Ś.SS. and W.Ł.; validation, W.Ł.

Funding: This research was funded by the Polish National Center for Research and Development (NCBR), grant number: STRATEGMED3/306888/3/NCBR/2017, project iTE “Method of treatment of large bone defects in oncological patients using in vivo tissue engineering approach". 
Acknowledgments: Part of the research project was carried out with the use of equipment funded by the project CePT, reference: POIG.02.02.00-14-024/08, financed by the European Regional Development Fund within the Operational Programme "Innovative Economy" for 2007-2013. The authors are grateful to Jan Mizeracki for expert assistance with SEM and Jacek Wojnarowicz for editing help.

Conflicts of Interest: The authors declare no conflict of interest.

\section{References}

1. Guozhong, C. Emergence of nanotechnology. In Nanostructures and Nanomaterials Synthesis, Properties and Applications; Chog, S., Narayanan, L., Eds.; Imperial College Press: London, UK, 2004; pp. 4-7, ISBN 1-86094-4159.

2. Favier, I.; Pla, D.; Gómez, M. Metal-based nanoparticles dispersed in glycerol: An efficient approach for catalysis. Catal. Today 2018, 310, 98-106. [CrossRef]

3. Mancin, F.; Prins, L.J.; Scrimin, P. Catalysis on gold-nanoparticle-passivating monolayers. Curr. Opin. Colloid Interface Sci. 2013, 18, 61-69. [CrossRef]

4. Gao, F.; Rajathurai, K.; Cui, Q.; Zhou, G.; Nkengforacha, I.; Gu, Z. Effect of surface oxide on the melting behavior of lead-free solder nanowires and nanorods. Appl. Surf. Sci. 2012, 258, 7507-7514. [CrossRef]

5. Mishra, R.; Zemanova, A.; Kroupa, A.; Flandorfer, H.; Ipser, H. Synthesis and characterization of Sn-rich $\mathrm{Ni}-\mathrm{Sb}-\mathrm{Sn}$ nanosolders. J. Alloy. Compd. 2012, 513, 224-229. [CrossRef]

6. Wu, M.; Wang, X.; Wang, K.; Guo, Z. An ultrasensitive fluorescent nanosensor for trypsin based on upconversion nanoparticles. Talanta 2017, 174, 797-802. [CrossRef]

7. Zhang, C.Y.; Yeh, H.C.; Kuroki, M.T.; Wang, T.H. Single-quantum-dot-based DNA nanosensor. Nat. Mater. 2005, 4, 826-831. [CrossRef]

8. Zhang, J.; Dichiara, A.; Novosselov, I.; Gao, D.; Chung, J.H. Polyacrylic acid coated carbon nanotube-paper composites for humidity and moisture sensing. J. Mater. Chem. C 2019, 7, 5374-5380. [CrossRef]

9. Woźniak, B.; Szałaj, U.; Chodara, A.; Mizeracki, J.; Łojkowski, M.; Myszka, D.; Łojkowski, W. Mechanism for sonocoating a polymer surface with nano-hydroxyapatite. Mater. Lett. 2019, 249, 155-159. [CrossRef]

10. Nastulyavichus, A.; Kudryashova, S.; Smirnov, N.; Saraeva, I.; Rudenko, A.; Tolordava, E.; Ionin, A.; Romanova, Y.; Zayarny, D. Antibacterial coatings of Se and Si nanoparticles. Appl. Surf. Sci. 2019, 469, 220-225. [CrossRef]

11. Lin, C.J. Structure and properties of hydroxyapatite for biomedical applications. In Hydroxyapatite (HAp) for Biomedical Applications; Mucalo, M., Ed.; Woodhead Publishing: Cambridge, UK, 2015; Volume 95, pp. 3-19, ISBN-10: 1782420339.

12. Alobeedallah, H.; Ellis, J.L.; Rohanizadeh, R.; Coster, H.; Dehghani, F. Preparation of nanostructured hydroxyapatite in organic lvents for clinical applications. Trends Biomater. Artif. Organs 2011, 25, 12-19.

13. Szczes, A.; Holysz, L.; Chibowski, E. Synthesis of hydroxyapatite for biomedical applications. Adv. Colloid Interface Sci. 2017, 249, 1-10. [CrossRef] [PubMed]

14. Rogowska-Tylman, J.; Locsc, J.; Salma, I.; Woźniak, B.; Pilmane, M.; Zalite, V.; Wojnarowicz, J.; Kędzierska-Sara, A.; Chudoba, T.; Szlązak, K.; et al. In vivo and in vitro study of a novel nanohydroxyapatite sonocoated scaffolds for enhanced bone regeneration. Mater. Sci. Eng. C 2019, 99, 669-684. [CrossRef] [PubMed]

15. Jaworski, S.; Wierzbicki, M.; Sawosz, E.; Jung, A.; Gielerak, G.; Biernat, J.; Jaremek, H.; Łojkowski, W.; Woźniak, B.; Wojnarowicz, J.; et al. Graphene oxide-based nanocomposites decorated with silver nanoparticles as an antibacterial agent. Nanoscale Res. Lett. 2018, 13, 116. [CrossRef] [PubMed]

16. Jędrzak, A.; Grześkowiak, B.F.; Coy, E.; Wojnarowicz, J.; Szutkowski, K.; Jurg, S.; Jesionowski, T.; Mrówczyński, R. Dendrimer based theranostic nanostructures for combined chemo- and photothermal therapy of liver cancer cells in vitro. Colloids Surf. B 2019, 173, 698-708. [CrossRef]

17. Sheth, P.; Sandhu, H.; Singhal, D.; Malick, W.; Shah, N.; Serphil, K.M. Nanoparticles in the pharmaceutical industry and the use of supercritical fluid technologies for nanoparticle production. Curr. Drug Deliv. 2012, 9, 269-284. [CrossRef] [PubMed]

18. Jamsheera, A.F.; Kupwade-Patilb, K.; Büyüköztürkb, O.; Bumajdada, A. Analysis of engineered cement paste using silica nanoparticles and metakaolin using 29Si NMR, water adsorption and synchrotron X-ray Diffraction. Const. Build. Mater. 2018, 180, 698-709. [CrossRef] 
19. Thiel, P.A.; Madey, T.E. The interaction of water with solidsurfaces-Fundamental-aspects. Surf. Sci. Rep. 1987, 7, 211-385. [CrossRef]

20. Bose, S.; Tarafder, S.; Bandyopadhyay, A. Biomaterials. In Hydroxyapatite (Hap) for Biomedical Applications; Mucalo, M., Ed.; Woodhead Publishing: Cambridge, UK, 2015; pp. 143-157. [CrossRef]

21. Chen, L.; Yu, Q.; Wang, Y.; Li, H. BisGMA/TEGDMA dental composite containing high aspect-ratio hydroxyapatite nanofibers. Dent. Mater. 2011, 27, 1187-1195. [CrossRef] [PubMed]

22. Sadat-Shojai, M.; Atai, M.; Nodehi, A.; Khanlar, L.N. Hydroxyapatite nanorods as novel fillers for improving the properties of dental adhesives: Synthesis and application. Dent. Mater. 2010, 26, 471-482. [CrossRef] [PubMed]

23. Ong, J.L.; Chan, D.C.N. Hydroxyapatite and their use as coatings in dental implants: A review. Crit. Rev. Biomed. Eng. 2000, 28, 667-707. [CrossRef] [PubMed]

24. Pokrowiecki, R.; Pałka, K.; Mielczarek, A. Nanomaterials in dentistry: A cornerstone or a black box? Nanomedicine 2018, 13, 639-667. [CrossRef] [PubMed]

25. Meskinfam, M.; Sadjadi, M.A.S.; Jazdarreh, H.; Zare, K. Biocompatibility evaluation of nano hydroxyapatite-starch biocomposites. J. Biomed. Nanotechnol. 2011, 7, 455-459. [CrossRef] [PubMed]

26. Zhang, Z.; Kurita, H.; Kobayashi, H.; Kurashina, K. Osteoinduction with HA/TCP ceramics of different composition and porous structure in rabbits. Oral Sci. Inter. 2005, 2, 85-95. [CrossRef]

27. Zhang, Z.; Zhang, S.; Shang, L. Apatite-coated polymer template for implant and drug delivery. In Hydroxyapatite Coating for Biomedical Applications; Zhang, S., Ed.; CRC Press: Boca Raton, FL, USA, 2013; pp. 239-288.

28. Dry, M.E.; Beebe, R.A. Adsorption studies on bone mineral and synthetic hydroxyapatite. J. Phys. Chem. 1960, 29, 1300-1304. [CrossRef]

29. Rootary, H.M.; Craig, R.G. Vapour phase adsorption of water on hydroxyapatite. J. Dent. Res. 1977, 56, 1437-1448. [CrossRef] [PubMed]

30. Holmes, J.M.; Beebe, R.A.; Posner, A.S.; Harper, R.A. Surface areas of synthetic calcium phosphates and bone mineral. Exp. Biol. Med. 1971, 133, 1250-1253. [CrossRef] [PubMed]

31. Wade, J.B.; Martin, G.P.; Long, D.F. A methodological approach for determining the effect of moisture content on the compaction properties of powders: Granular hydroxyapatite. Powder Technol. 2013, 246, 511-519. [CrossRef]

32. Kuśnieruk, S.; Wojnarowicz, J.; Chodara, A.; Chudoba, T.; Gierlotka, S.; Lojkowski, W. Influence of hydrothermal synthesis parameters on the properties of hydroxyapatite nanoparticles. Beilstein J. Nanotechnol. 2016, 7, 1586-1601. [CrossRef] [PubMed]

33. Nakamura, T.; Yamashita, K.; Neo, M. Remineralization potential of new toothpaste containing nano-hydroxyapatite. Key Eng. Mater. 2006, 647, 139-144. [CrossRef]

34. Niamtu, J., 3rd. New lip and wrinkle fillers. Oral Maxillofac. Surg. Clin. N. Am. 2005, 17, 17-28. [CrossRef] [PubMed]

35. Dick, T.A.; Dos Santos, L.A. In situ synthesis and characterization of hydroxyapatite/natural rubber composites for biomedical applications. Mater. Sci. Eng. C 2017, 77, 874-882. [CrossRef] [PubMed]

36. Miyazaki, T.; Kawashita, M. Electrochemical deposition of hydroxyapatite and its biomedical applications. In Hydroxyapatite Coatings for Biomedical Applications; Zhang, S., Ed.; CRC Press: Boca Raton, FL, USA, 2013; pp. 31-55. [CrossRef]

37. Franklin-Ford, T.W.; Suarez-Gonzalez, D.; Sung Lee, J.; Murphy, W.L. Biomimetic hydroxyapatite materials for therapeutic delivery. In Hydroxyapatite Synthesis, Properties and Applications; Zhang, S., Ed.; CRC Press: New York, NY, USA, 2012; pp. 201-239.

38. Wang, X.; Li, Y.; Wei, J.; De Groot, K. Development of biomimetic nano-hydroxyapatite/poly(hexamethylene adipamide) composites. Biomaterials 2002, 23, 4787-4791. [CrossRef]

39. Le Bolay, N.; Lamure, A.; Gallego Leis, N.; Subhani, A. How to combine a hydrophobic matrix and a hydrophilic filler without adding a compatibilizer-Co-grinding enhances use properties of Renewable PLA-starch composites. Chem. Eng. Process. 2012, 56, 1-9. [CrossRef]

40. Bangudu, A.B.; Pilpel, N. Effects of composition, moisture and stearic acid on the plasto-elasticity and tableting of paracetamol-microcrystalline cellulose mixtures. J. Pharm. Pharmacol. 1985, 5, 289-293. [CrossRef] [PubMed] 
41. Abboud, M.; Turner, M.; Duguet, E.; Fontanille, M. PMMA-based composite materials with reactive ceramic fillers PMMA-based composite materials with reactive ceramic fillers. J. Mater. Chem. 1997, 7, 1527-1532. [CrossRef]

42. Hong, Z.; Zhang, P.; He, C.; Qiu, X.; Liu, A.; Chem, L.; Chen, X.; Jing, X. Nano-composite of poly(L-lactide) and surface grafted hydroxyapatite: Mechanical properties and biocompatibility. Biomaterials 2005, 26, 6296-6304. [CrossRef]

43. Wang, T. Improve the strength of PLA/HA composite through the use of surface initiated polymerization and phosphonic acid coupling agent. J. Res. Natl. Inst. Stand. Technol. 2011, 116, 785-796. [CrossRef]

44. Nokhodchi, A.; Rubinstein, M.H.; Larhirb, H.; Guyot, J.C. The effect of moisture on the properties of ibuprofen tablets. Int. J. Pharmac. 1995, 118, 191-197. [CrossRef]

45. Garr, J.S.M.; Rubinstein, M.H. The influence of moisture on consolidation and compaction properties of paracetamol. Int. J. Pharmac. 1992, 81, 187-192. [CrossRef]

46. Thapa, P.; Lee, A.R.; Choi, D.H.; Jeong, S.H. Effects of moisture content and compression pressure of various deforming granules on the physical properties of tablets. Powder Technol. 2017, 310, 92-102. [CrossRef]

47. Muti, H.; Othman, S. Effects of binders and moisture content on the disintegration, hardness and friability of paracetamol and orphenadrine citrate tablets. Drug Dev. Ind. Pharm. 1989, 15, 2017-2035. [CrossRef]

48. Smolen, D.; Kedzierska, A.; Pietrzykowska, E.; Chudoba, T.; Lojkowski, W.; Swieszkowski, W.; Kurzydlowski, K. Method for Producing Synthetic Hydroxyapatite Nanoplates and Nanopowder Containing Synthetic Hydroxyapatite Nanoplate. WO2014162167A1, 9 October 2014.

49. Opalinska, A.; Leonelli, C.; Lojkowski, W.; Pielaszek, R.; Grzanka, E.; Chudoba, T.; Matysiak, H.; Wejrzanowski, T.; Kurzydlowski, K.J. Effect of Pressure on Synthesis of Pr-Doped Zirconia Powders Produced by Microwave-Driven Hydrothermal Reaction. J. Nanomater. 2006, 2006, 98769. [CrossRef]

50. Wojnarowicz, J.; Chudoba, T.; Gierlotka, S.; Lojkowski, W. Effect of microwave radiation power on the size of aggregates of ZnO NPs prepared using microwave solvothermal synthesis. Nanomaterials 2018, 8, 343. [CrossRef] [PubMed]

51. Wojnarowicz, J.; Chudoba, T.; Gierlotka, S.; Sobczak, K.; Lojkowski, W. Size control of cobalt-doped ZnO nanoparticles obtained in microwave solvothermal synthesis. Crystals 2018, 8, 179. [CrossRef]

52. Wojnarowicz, J.; Mukhovskyi, R.; Pietrzykowska, E.; Kusnieruk, S.; Mizeracki, J.; Lojkowski, W. Microwave solvothermal synthesis and characterization of manganese-doped ZnO nanoparticles. Beilstein J. Nanotechnol. 2016, 7, 721-732. [CrossRef]

53. Wojnarowicz, J.; Opalinska, A.; Chudoba, T.; Gierlotka, S.; Mukhovskyi, R.; Pietrzykowska, E.; Sobczak, K.; Lojkowski, W. Effect of water content in ethylene glycol solvent on the size of $\mathrm{ZnO}$ nanoparticles prepared using microwave solvothermal synthesis. J. Nanomater. 2016, 2016, 2789871. [CrossRef]

54. Wojnarowicz, J.; Chudoba, T.; Koltsov, I.; Gierlotka, S.; Dworakowska, S.; Lojkowski, W. Size control mechanism of ZnO nanoparticles obtained in microwave solvothermal synthesis. Nanotechnology 2018, 29, 065601. [CrossRef]

55. Lojkowski, W.; Leonelli, C.; Chudoba, T.; Wojnarowicz, J.; Majcher, A.; Mazurkiewicz, A. High-energy-low-temperature technologies for the synthesis of nanoparticles: Microwaves and high pressure. Inorganics 2014, 2, 606-619. [CrossRef]

56. Nanda, K. Liquid-drop model for the surface energy of nanoparticles. Phys. Lett. A 2012, 376, 1647-1649. [CrossRef]

57. Lu, H.M.; Jiang, Q. Size-dependent surface energies of nanocrystals. J. Phys. Chem. B 2004, 108, 5617-5619. [CrossRef]

58. Majcher, A.; Wiejak, J.; Przybylski, J.; Chudoba, T.; Wojnarowicz, J. A novel reactor for microwave hydrothermal scale-up nanopowder synthesis. Int. J. Chem. React. Eng. 2013, 11, 361-368. [CrossRef]

59. Dabrowska, S.; Chudoba, T.; Wojnarowicz, J.; Łojkowski, W. Current trends in the development of microwave reactors for the synthesis of nanomaterials in laboratories and industries: A review. Crystals 2018, 8, 379. [CrossRef]

60. Pielaszek, R. Analytical expression for diffraction line profile for polydispersive powders. Appl. Crystallogr. Proc. XIX Conf. 2004, 43-50. [CrossRef]

61. Pielaszek, R. FW15/45M method for determination of the grain size distribution from powder diffraction line profile. J. Alloy. Compd. 2004, 37, 128-132. [CrossRef] 
62. Opalinska, A.; Malka, I.; Dzwolak, W.; Chudoba, T.; Presz, A.; Lojkowski, W. Size-dependent density of zirconia nanoparticles. Belistein J. Nanotechnol. 2015, 6, 27-35. [CrossRef] [PubMed]

63. Pigoń, K.; Ruziewicz, Z. Adsorpcja. In Chemia Fizyczna; PWN: Waraw, Poland, 1980; pp. 323-329, ISBN 9788301150549.

64. Pickett, G. Modification of the Brunauer-Emmett-Teller theory of multimolecular adsorption. J. Am. Chem. Soc. 1945, 67, 1958-1962. [CrossRef]

65. Chung, Y.W. Atomic and molecular bonding. In Introduction to Materials Science and Engineering; Chung, Y.W., Ed.; CRC Press Taylor \& Francis: Boca Raton, FL, USA, 2006; p. 16, ISBN-10:0849392632.

66. Quadros, M.E.; Marr, L.C. Environmental and human health risks of aerosolized silver nanoparticles. J. Air Waste Manag. Assoc. 2010, 60, 770-781. [CrossRef]

67. Armstrong, N.A.; Patel, A. The compressional properties of dextrose monohydrate and anhydrous dextrose of varying water contents. Drug Dev. Ind. Pharm. 1986, 12, 1885-1901. [CrossRef]

(C) 2019 by the authors. Licensee MDPI, Basel, Switzerland. This article is an open access article distributed under the terms and conditions of the Creative Commons Attribution (CC BY) license (http://creativecommons.org/licenses/by/4.0/). 